\title{
Bisexuality: definition, humanistic profiles, neural correlates and
}

\section{clinical hypotheses}

\section{Giulio Perrotta}

Psychologist sp.ing in psychotherapy with a strategic approach, Forensic Criminologist expert in sectarian cults, esoteric and security profiles, Jurist sp.ed SSPL, Essayist

Corresponding Author: Giulio Perrotta, Psychologist sp.ing in psychotherapy with a strategic approach, Forensic Criminologist expert in sectarian cults, esoteric and security profiles, Jurist sp.ed SSPL, Essayist.

Received date: September 26, 2020; Accepted date: October 12, 2020; Published date: October $19,2020$.

Citation: Perrotta G., (2020) Bisexuality: definition, humanistic profiles, neural correlates and clinical hypotheses. J Neuroscience and Neurological Surgery. 6(5); DOI:10.31579/2578-8868/138

Copyright: () 2020 Giulio Perrotta, This is an open-access article distributed under the terms of the Creative Commons Attribution License, which permits unrestricted use, distribution, and reproduction in any medium, provided the original author and source are credited.

\section{Abstract}

This work focuses on the study of neurobiological and functional profiles in terms of bisexuality, to carefully evaluate the direct correlation between anatomical and physiological elements and the choice of sexual preferences oriented on both sexes, hypothesizing any clinical profiles.

Keywords: Agraphia; neurobiological; neurogenetic field

\section{Definition and humanistic profiles}

According to the current position of the scientific community, "bisexuality" can be considered as a sexual orientation that is substantiated in experiencing attraction, drive and emotions, linked to the affective and sexual sphere both for one's sex and for the opposite sex. In the clinical setting, the status of "bisexuality" has always been nosographically absorbed by the general category of homosexuality, almost as if it were one of its ribs. Bisexuality has been known since ancient times and, historically, society's evaluation of this phenomenon has gone through alternate phases: appreciated by Greek civilization (which, however, did not accept only homosexual relationships), tolerated (depending on context) by Roman civilization, but condemned by the Judeo-Christian tradition. [1]

From the second half of the twentieth century, the first idea of "homosexuality" was declassified, moving from the psychopathological condition inherent to the sociopathic personality disorders of the 1954 version of the DSM to the sexual deviance of 1968, only to gradually become an ego-dystonic form of one's own in 1974 sexual perception and finally a natural sexual orientation only in 1987 and in the revised version of 1990, being finally decriminalized reeds by the International Statistical Classification of Diseases, Accidents, and Causes of Death (ICD) of 17 May 1990, although psychoanalytic thinking was well oriented towards the opposite; in fact, homosexuality had hitherto been considered a morbid obsession (Charcot), sexual psychopathy (von Krafft-Ebing), an arrest of normal development (S. Freud), a narcissistic fixation (Mann and Ferenczi), a neurotic escape (Adler) or a parapathic neurosis that originates from the conflict between instinct and inhibition (Stekel). In particular, Freud spoke, with great scandal for that time, of the "perverse polymorphic" child, that is, with the potential possibility of having any type of sexual activity and who, only through education and culture, then makes a more defined choice. He wrote: "A certain degree of anatomical hermaphroditism is typical of normality: in no individual of normal male or female training are there traces of the apparatus of the opposite sex which, or continued to exist, without having a function, as rudimentary organs or they have been transformed to take on other functions". And again: "the proportion with which the male and female intertwine in the individual is subject to very significant oscillations". The father of psychoanalysis took the ancient Greeks as an example: "Among the Greeks, among whom the most virile men appear among the inverted, it is clear that not the boy's virile character, but his physical proximity to the woman, as well as his female psychic qualities - shyness, restraint, the need to learn, to be helped - ignited man's love. Having become a man, the boy ceased to be a sexual object for man and perhaps became a pederast himself. In this case, therefore, the sexual object, as in many cases, is not the same sex, but the union of the characters of the two sexes, almost the compromise between an impulse that requires the man and another that requires the woman, firm while remaining the condition of the virility of the body (of the genitals), so to speak the mirroring of one's bisexual nature". However, this evolution has certainly led to an opening towards social rights but also to a fluidity in sexual orientation, where the main problems emerge especially in the bisexual position. [2] [5] With reference therefore to bisexuality, understood as the choice of sexual orientation to bind sentimentally and sexually to both women and men, the discussion takes on broader and characterizing contours, precisely because of the less defined and precise nature of the sexual orientation choice. The aforementioned fluidity on sexual orientation leads to rather bizarre decisionmaking developments and often motivated by unconscious dynamics not better identified even by the subjects: [2]

a) "bi-curiosity", understood as a series of limited and sporadic behaviors about the desire to approach sexually individuals of the same sex, but who do not have the characteristic of persistence and recurrence over time; 
$\mathrm{J}$ Neuroscience and Neurological Surgery

b) "bi-chic", a term describes people who engage in seductive relationships with both men and women to make people talk about themselves in a glamorous perspective;

c) "bi-permissive", understood as the subject who does not actively seek sexual relations with people of a specific sex but who is "open", that is, available to make new experiences;

d) "Bi-for pay-bi": the term is applied to people who call themselves heterosexual but who engage in sexual relations with people of the same sex in exchange for money;

e) "Heteroflexibility": this term of American origin, often used derisively or to deny one's bisexuality, refers to a predominantly straight individual, but who can engage in a homosexual relationship occasionally because he is temporarily in a favorable context to it;

f) "Lesbians until graduation": this term describes young British (and American) women who, during their years of study at university, engage in relations with other women, to then adopt, once they graduate, a strictly heterosexual attitude and end up getting married with a man.

Kinsey, author of the editorial work "Sexual behavior in the human male", proposed a taxonomic scale, which suggested a value from 0 to 6 , to describe those who were exclusively heterosexual (value 0), by those who considered themselves predominantly straight but with homosexual tendencies (value 1), with homosexual components (value 2), bisexual (value 3), mainly homosexual with heterosexual components (value 4), with heterosexual tendencies (value 5) and finally exclusively homosexual (value 6). However, this approach does not completely exhaust the complexity of sexual orientation. In the academic field, therefore, the issue of bisexuality as an innate orientation or consequence of factors is still strongly discussed. [2]

The strong interdependence between the concept of "bisexuality" and "homosexuality" therefore appears evident, despite representing two different dimensions. This also happens because there is a widespread belief in the community, in the absence of targeted scientific studies, that bisexuality is a transitory phase that should lead the person to complete acceptance of his homosexual nature; these beliefs are strengthened by some investigations that elaborate certainties on statistical bases (with unrepresentative samples) such as those which support the following: bisexuals experience friendship and family ties in a significantly less stable and lasting way than homosexuals; bisexuals are more likely to experience unequal treatment in the workplace and intrapersonal settings; bisexuals have greater difficulties in living a monogamous relationship, being more oriented towards polygamy. [3-5]

The social identity of the bisexual is still strongly conditioned by the difficult acceptance of the concept of homosexuality and as such, the interdependence between the two dimensions slows the natural progress of the acceptance process also at the socio-cultural and anthropological level of the former; this difficulty is also accentuated by the clinical hypothesis, not verified statistically, with a representative sample, that bisexuality is a paraphilia. [6]

What is evident from the scientific research published so far is that:

1) bisexuality is distinct from the homosexual dimension, even if they have the same sexual and sentimental attraction for people of the same sex. The sexual orientation is not unchanged over time and many factors favor the fluidity of the sexual gender, especially in the case of bisexuality. Also, men and women who identify themselves openly bisexual demonstrate a model of sexual interest that is truly geared towards both sexes, beyond gender, as they have a greater attraction for both sexes and less gender specificity than heterosexuals and homosexuals. [7]

2) female bisexuality seems to be more widespread than male bisexuality, even if the data could be conditioned by a difficulty of acceptance
Copy rights@ Giulio Perrotta,

linked to socio-environmental and cultural components, which have mostly cleared female bisexuality as a male erotic fantasy, therefore women they feel judged less than men (however, even in this case, the statistical sample was not representative). [8] [12]

3) bisexuality is subject to discrimination by homosexuals and heterosexuals themselves because bisexuals (due to stereotypes, preconceptions and socio-cultural prejudices) are considered incapable of taking a firm and decisive sexual position concerning the preferred sexual gender (also because it is not this choice always translates into a definitive position on the part of the bisexual) and therefore they avoid sexual relations with the bisexuals, probably also for fear that they may be betrayed or abandoned in favor of the opposite sex. [9] A recent metanalysis work by Ross has highlighted the negative consequences of biphobia concerning anxious and depressive symptoms. Their research showed that, compared to heterosexual people, but also compared to gay men and lesbian, bisexual people are more likely to experience anxiety and depression. This is precisely adduced to the whole series of beliefs, stereotypes, and prejudices that feed the negative attitudes of biphobia, which bisexual people are forced to undergo. The work of Israel and Mohr classified these beliefs, already collected and explored in Eliason's early studies, identifying three macro-categories of negative beliefs about bisexuality: a) authenticity: different types of stereotypes are linked to the authenticity and existence of the bisexuality (bisexuals are confused about their sexuality, bisexuals are gay and lesbian people who are afraid to admit it or bisexuality is only a phase of experimentation); b) sexuality: some attitudes towards bisexual people focus on their sexuality (bisexual people tend to have more sexual partners than heterosexuals or gays and lesbians, bisexual people have more flexible attitudes about sex than heterosexual and bisexual people spread AIDS in the heterosexual and homosexual community); c) loyalty: other prejudices pertain to the sphere of loyalty, in the sense of perception of loyalty, sincerity and loyalty to others: (bisexual people are more likely to have multiple sexual partners at the same time, a bisexual person is more likely to leave you for someone of opposite sex to you or bisexual people do not engage politically and socially like gays and lesbians). As can be seen, therefore, these beliefs, stereotypes, and prejudices are very specific and different from those commonly attributed to gay and lesbian people. Bisexuality is not synonymous with ambiguity. [13-21]

4) bisexuality does not presuppose hypersexuality or a greater predisposition to the intensification of sexual activity or the presence of any nosographically identified paraphilias identified in the clinical manuals. [10] Some data, on the other hand, report a greater intensity of sexual desire linked to the partner and to the highly eroticized circumstance, which makes bisexuals more inclined to sex. [61]

5) bisexuality does not imply proving the same attraction or desire for both sexes equally. Emotions are considered regardless of the gender of belonging. In general, sexual attraction is unbalanced towards one side or the other, also according to the period lived and the encounters. The bisexual feels attracted to the person as such, regardless of the sexual gender to which he belongs. The sexual choice of the bisexual, contrary to popular belief, does not affect both male and female partners at the same time, but it is completely random: this means that monogamous relationships can take place, even long term, with subjects of the same sex or of the opposite sex. Like heterosexuals, bisexuals can also have a monogamous relationship with a partner, and then occasionally betray him with another person, who in this case can be both man and woman. [11]

Based on what has been said so far, the writer proposes a theoretical classification to better frame "bisexuality" and its possible forms: [56]

a) mental images and fantasies with a sexual background, in an instinctive phase, that the person unwittingly produces, without however practicing acts of auto-eroticism or searching for the 
b) partner of the same sex, due to the lack of acceptance by the same of this orientation component (mental bisexuality)

c) fantasies, desires and sexual drives, in the ideational phase, that the person involuntarily uses or voluntarily produce to get excited and to enjoy, to practice masturbation, without ever going to the active phase of the search for the partner of the same sex, therefore limiting himself to imagination alone (passive bisexuality)

d) sexual attitudes, more or less expressed, aimed at finding a samesex partner to satisfy fantasies, desires and drives of a sexual nature (active bisexuality)

e) attitudes and behaviors of an effective and relational nature, more or less expressed, aimed at the search for a partner of the same sex with whom to share both the sexual and the personal aspect, without however reaching feelings capable of making the person desire to establish a stable, lasting and mature sentimental relationship (emotional bisexuality)

f) attitudes and behaviors of a sentimental nature, more or less expressed, aimed at the search for a partner of the same sex with whom to share both the sexual and the emotional aspect, coming to experience feelings that can make the person desire to establish a relationship stable, long-lasting and mature (sentimental bisexuality).

\section{The neural correlates}

The data confirming the substantial (and incorrect) absorption of the bisexual category in the macro-category of homosexuality are offered to us by scientific research which, although careful in distinguishing the two dimensions in theory, in practice does not happen [22-50] and the studies [51-60] that examine the bisexual category distinguishing it from the homosexual one; however, even these studies, recently temporally, are not on statistically representative samples. Trying to summarize therefore in terms of neural correlates in bisexuality these data emerge:

1) in female bisexuality, a particular feature of the functionality of the ventral striatum has been noted, an area typically known to be associated with desire. The subjective and neural responses of homosexual women were found to reflect a greater propensity towards female stimuli, compared to bisexual and heterosexual women, whose responses do not differ significantly. These patterns have also been suggested by analysis of the whole brain, with homosexual women showing specific activations (by category) of greater extension in the areas of visual and auditory processing. Bisexual women tended to show more mixed patterns, with activations more sensitive to female stimuli in the areas of sensory processing and activations more sensitive to male stimuli in the areas associated with social cognition.

2) in male bisexuality, the results of the studies are controversial and not very consistent. Bisexual men constantly exhibit bisexual subjective arousal patterns, but sometimes have shown category-specific genital arousal patterns. More recently, a study found bisexual genital arousal models that used particularly strict inclusion criteria for bisexuality, requiring that bisexual participants had at least two sexual partners and one romantic partner (three months or longer in duration) each gender. Even more recently, studies of subjective and genital sexual arousal in monosexual (i.e. heterosexual and homosexual) men have repeatedly found that erotic stimuli describing men's favorite sex produce strong responses, while erotic stimuli depicting the other sex they produce many more weak responses. Inconsistent results have previously been obtained in bisexual men, who sometimes showed distinctly bisexual responses, but other times they showed patterns more similar to those observed in monosexual men. By always paying attention to the ventral striatum, bisexual men tended to show less differentiation between male and female stimuli, as well as in other areas, such as the occipital and temporal cortex and the anterior and orbital-front cingulate.

\section{Clinical hypotheses}

Sexual orientation is therefore commonly debated as a characteristic of the individual, as well as for biological sex, gender identity, or age. However, this perspective is incomplete, since sexual orientation is always defined based on relational terms and necessarily concerns relationships with other individuals. Sexual acts and romantic attractions are categorized as homosexual or heterosexual based on the biological sex of the individual involved in them, relative to the partners. Indeed, it is through performance - or the desire to lend - with another person that individuals express their heterosexuality, homosexuality, or bisexuality. Thus, sexual orientation is fully connected to the intimate personal relationships that human beings form with others to meet their deepest sentimental needs for love, bond, and intimacy. In addition to sexual behavior, these constraints include notsexual physical affections between partners, sharing goals and values, mutual support, and constant commitment. Consequently, sexual orientation is not merely a personal characteristic that can be defined in isolation. Likewise, one's sexual orientation defines the universe of people with whom a person can find satisfying and fulfilling relationships which, for many individuals, comprise an essential component of personal identity. [2]

On the subject of "bisexuality", the etiological theories that try to explain this sexual dimension are essentially four:

1) bisexuality is a "sexual orientation", which does not present pathological features, as was believed in the last century, and has equal dignity of homosexuality and heterosexuality. [3] This approach, supported by the entire scientific community, is also supported by the socio-cultural, political, and anthropological movements that have fought for the derubrication of the non-heterosexual dimensions in the manuals of psychopathology from orientation disorder. [6] Recent neuroscientific discoveries, however, highlight a rather contradictory aspect of this derubrication (which has the flavor more than a political action and less than an intervention of clinical value): the neurocerebral structures of a homosexual and bisexual brain are significantly different in size and function from a heterosexual brain, exactly as it happens in any other psychopathological condition nosographically framed. [2, 62]

2) bisexuality, not being framed canonically in the homosexual and heterosexual dimensions, must, therefore, embody the manifestation of a paraphilia, which is substantiated in experiencing excitement towards the same sex, while experiencing heterosexual attractions and instincts. This hypothesis recalls the psychoanalytic concept of S. Freud, influenced by Fliess, according to which every human being constitutionally has both male and female sexual dispositions, which are found in the conflicts that the subject tries to assume his sex. The father of psychoanalysis emphasizes the importance of bisexuality, especially concerning the Oedipus complex: a) it determines the outcome of the Oedipal situation: in both sexes, the relative intensity of the male and female sexual disposition is what determines whether the outcome of the Oedipal situation will be identified with the father or mother. This is one of how bisexuality intervenes in the subsequent events of the Oedipus complex; $b$ ) it is responsible for the more or less complete development (positive and negative) of the Oedipus complex. This means that a child does not simply have an ambivalent attitude towards the father, while the object-choice of the mother is directed exclusively by a current of tenderness; but who instead behaves simultaneously as a child, showing an attitude of female tenderness towards the father with a corresponding hostility and jealousy towards the mother. It is this complication introduced by bisexuality that makes it so difficult to arrive at a clear vision of the facts connected with the very first identifications and object choices. It can even be said that the ambivalence shown in the relationship with the parents must be entirely attributed to bisexuality and that it is not developed in identification due to the effect of rivalry; c) at sunset of the oedipal complex, bisexuality determines the relative intensity of 
3) the identifications: at sunset of the oedipal complex the four tendencies of which it is composed will group to produce an identification with the father and one with the mother. The relative intensity of the two identifications will reflect the preponderance of either of the two sexual dispositions of each individual. If therefore all people have an essentially bisexual nature, according to Freud, in those declaredly heterosexual the homosexual component would only be repressed in the unconscious but not suppressed, it would be in a latent state, but it could manifest itself in very different forms, sometimes in form sublimated as mental disorders. The disturbance deriving from one's homosexual component and the refusal to accept it would be the psychological cause of the presumption to consider only heterosexual behavior as normal and the attempt to rationally justify this claim, a claim that is considered as dilating the fear of one's homosexual component to the homosexuality in general, that is, as homophobia. [6]

4) bisexuality is the consequence of a psychological trauma, resulting from a dysfunctional attachment [63] or a destabilizing sexual event in the early years of childhood [64]. These hypotheses are not currently reflected in the scientific community, although some studies have shown the neuronal correlation between traumatized brains [65] and the brains of people sexually-oriented towards homosexuality [2]. Furthermore, recent work has shown that social information is already processed differently in primary sensory cortices. Converging evidence suggests that prefrontal areas contribute to the process of social interaction and the determination of social hierarchies. In social interactions, we identify the gender in seconds, but after centuries of anatomy we are still unable to distinguish the male and female cortex. New data reinforce the idea of a bisexual cortical anatomy layout. Physiological analysis, however, has provided evidence of sex differences in cortical processing. Unlike other cortical circuits, sexual processing circuits undergo major rewiring and expansion during puberty and show permanent damage due to child abuse. [69]

bisexuality has a biological basis and must be sought in genetic predisposition [66] and hormonal profiles [67-68]. In particular, recent research has shown, with a statistically representative sample, that genes affect a percentage ranging from 8 to 25 (percent) and therefore we can only speak of predisposition and not of bisexuality or genetic homosexuality. Concerning hormonal values, especially in the gestation phase, recent research has shown that during the intrauterine period, an increase in testosterone masculinizes the fetal brain, while the absence of such an increase causes a brain with more feminine features. Since sexual differentiation of the brain occurs at a much more advanced stage of development than sexual differentiation of the genitals, these two processes can be influenced independently of each other. Sexual differences in cognition, gender identity (an individual's perception of their sexual identity), sexual orientation (heterosexuality, homosexuality, or bisexuality), and the risks of developing neuropsychiatric disorders (such as paraphilias) are therefore programmed in our brain during early development. There is no evidence that one's postnatal social environment plays a crucial role in gender identity or sexual orientation, other than as an etiological contributing factor, to be accused of a process more akin to psychological trauma or dysfunctional attachment.

\section{Conclusions}

There are well-founded reasons, neurobiological, genetic, psychodynamic, and socio-environmental, to question the derubrication of bisexuality, from a clinical point of view. The research currently published cannot satisfy the need for clarification regarding the subject of this publication and therefore we refer to a subsequent historical moment to resume the discussion from an exclusively clinical point of view.
5)

In the future, research should focus on the following investigation points:

a) studies aimed at distinguishing paraphilic forms from definitive orientation choices;

b) studies aimed at finding any differences between heterosexual, homosexual and bisexual subjects concerning brain structures and the levels of serum markers of sexual steroids, both in fetuses and in adults, in all its evolutionary development, thus highlighting any conditioning can lead to certain sexual orientation choices other than heterosexuality;

c) studies able to determine the precise direction of the neural circuits underlying sexual preferences, comparing the results with heterosexual subjects;

d) studies able to focus research on genetic factors capable of influencing sexual orientation.

The direct and indirect implications on the confirmation of the clinical hypothesis of the bisexual condition would bring further complications, concerning the management of the patients' treatments and therapies, while making important differences between highly adaptive patients and those who perceive their condition as dysfunctional concerning the surrounding environment.

The question to ask, in this theoretical hypothesis, is whether we must intervene clinically to correct the bisexual condition and lead the patient towards a heterosexual orientation, or simply accompany him towards a better perception of his emotions, desires and needs strategically. [70] What seems certain is that the static and nosographic evaluation of "mental illness" about bisexuality is not at stake, the more the awareness of a clinical reality concerning the topic treated and the evaluation by the therapist of any anamnestic profiles related to high adaptive functionality or the patient's ego-dystonic and dysfunctional perception.

The confirmation of the clinical nature of bisexuality could also revive or reawaken the theses set aside in the last century on possible therapies aimed at correcting dysfunctional sexual orientation, through psychotherapy (mainly post-Freudian dynamic orientation) or the use of neurostimulation equipment (for example electroshock), with a whole series of ethical, moral, social, political and psychological implications that are not indifferent to the daily needs of the patients.

These profiles must necessarily be directed to the appropriate research sites, carefully evaluating the patient's medical history and whether his or her choice of sexual orientation is experienced or not by the patient in a highly adaptive or dysfunctional way.

In general, even if the clinical nature of the not-heterosexual choice proves, this condition should not in itself justify treatments contrary to the dignity and will of the person. The scientific evidence received so far is not definitive and deserves further investigation to reach meaningful conclusions capable of determining collective awareness.

\section{References}

1. Perrotta G (2019) Psicologia generale, Luxco Ed., 1st ed.

2. Perrotta G (2020) Sexual orientations: a critical review of psychological, clinical and neurobiological profiles. Clinical hypothesis of homosexual and bisexual positions. Review article, Author. International Journal of Sexual and Reproductive Health Care, Int J Sex Reprod Health Care 3(1): 027-041, doi: 10.17352/ijsrhc.000012. 
3. APA (2011) Practice Guidelines for LGB Clients. Guidelines for Psychological Practice with Lesbian, Gay, and Bisexual Clients.

4. Bashian HM (2018) Bisexual older adult women: A review of the literature, Adult Development \& Aging, APA.

5. Perrotta G (2019) Psicologia clinica, Luxco Ed., 1th ed.

6. Perrotta G (2019) Psicologia dinamica, Luxco Ed., 1th ed.

7. Rullo JE, Strassberg DS \& Miner MH (2015) Genderspecificity in sexual interest in bisexual men and women. Archives of Sexual Behavior; 44(5):1449-57, doi: 10.1007/s10508-014-0415-y.

8. Herbenick D, Reece M, Schick V, Sanders SA, Dodge B \& Fortenberry JD (2010) Sexual behaviour in the United States: results from a national probability sample of men and women aged 14-94 in Journal of Sexual Medicine, 7, pp. 255-265.

9. Feinstein BA et al (2014) Willingness to engage in romantic and sexual activities with bisexual partners: Gender and sexual orientation differences. Psychology of Sexual Orientation and Gender Diversity, 1(3), 255-262, doi: $10.1037 / \mathrm{sgd} 0000047$.

10. Lippa RA (2007) The Relation Between Sex Drive and Sexual Attraction to Men and Women: A Cross-National Study of Heterosexual, Bisexual, and Homosexual Men and Women. Archives of Sexual Behavior volume 36, pages 209222.

11. Rosenthal AM, Sylva D, Safron A \& Bailey JM (2011) Sexual arousal patterns of bisexual men revisited. Biological Psychology, 88, 112-115.

12. Diamond LM (2008) Female Bisexuality From Adolescence to Adulthood: Results From a 10-Year Longitudinal Study. Developmental Psychology; 44 (1): 5-14.

13. Eliason M (2001) Bi-negativity: The stigma facing bisexual men. Journal of Bisexuality, 1 (2/3), 137-154.

14. Eliason MJ (1996) A survey of the campus climate for lesbian, gay, and bisexual university members. Journal of Psychology \& Human Sexuality, 8 (4), 39-58.

15. Eliason MJ (1997) The prevalence and nature of biphobia in heterosexual under-graduate students. Archives of Sexual Behavior, 26 (3), 317-326.

16. Herek GM (2002) Heterosexuals' attitudes toward bisexual men and women in the United States. The Journal of Sex Research, 39 (4), 264-274.

17. Israel T \& Mohr JJ (2004) Attitudes toward bisexual women and men: Current research, future directions. Journal of Bisexuality, 4 (1-2), 117-134.

18. Mohr JJ \& Rochlen AB (1999) Measuring attitudes regarding bisexuality in lesbian, gay male, and heterosexual populations. Journal of Counseling Psychology, 46, 353369.

19. Ross LE, Salway T, Tarasoff LA, MacKay JM, Hawkins BW \& Fehr CP (2017) Prevalence of Depression and Anxiety Among Bisexual People Compared to Gay, Lesbian, and Heterosexual Individuals: A Systematic Review and Meta-Analysis. The Journal of Sex Research, 1-22.

20. Rust PC (1993) Neutralizing the political threat of the marginal woman: Lesbians' beliefs about bisexual women. Journal of Sex Research, 30 (3), 214-228.

21. Rust PC (1995) Bisexuality and the challenge to lesbian politics: Sex, loyalty, and revolution. New York: New York University Press.

22. Snell RS (2010) Clinical Neuroanatomy, 7th, Lippincott Williams \& Wilkins, p. 34, ISBN 978-0-7817-5993-9.
Copy rights@ Giulio Perrotta,

23. Blumenfeld H (2010) Neuroanatomy through clinical cases, 2nd, Sunderland, Mass., Sinauer Associates, p. 21, ISBN 978-0-87893-613-7.

24. Hofman MA (1995) Sexual differentiation of the human hypothalamus in relation to gender and sexual orientation, in Trends in Neurosciences, vol. 18, $n^{o}$ 6, pp. 26470, DOI:10.1016/0166-2236(95)80007-O, PMID 7571001.

25. LeVay $S$ (1991) A difference in hypothalamic structure between heterosexual and homosexual men, in Science, vol. 253, $n^{o}$ 5023, pp. 10347, DOI:10.1126/science.1887219, PMID 1887219.

26. Byne W, Lasco MS, Kemether E, Shinwari A, Edgar MA, Morgello S, Jones LB \& Tobet S (2000) The interstitial nuclei of the human anterior hypothalamus: an investigation of sexual variation in volume and cell size, number and density, in Brain Res, vol. 856, $n^{o} 1-2, \quad p p .254$ 8, DOI:10.1016/S0006-8993(99)02458-0, PMID 10677635.

27. Swaab DF, Hofman MA (1995) Sexual differentiation of the human hypothalamus in relation to gender and sexual orientation, in Trends in Neurosciences, vol. 18, $\mathrm{n}^{\circ} 6$, pp. 264-70, Doi: 10.1016/0166-2236(95)80007-O.

28. Swaab DF \& Hofman MA (1990) An enlarged suprachiasmatic nucleus in homosexual men., in Brain Res., vol. 537, $n^{o} 1-2$, dic 1990, pp. 141-8, DOI:10.1016/00068993(90)90350-K, PMID 2085769.

29. Abe C, Johansson E, Allzen E \& Savic I (2014) Sexual Orientation Related Differences in Cortical Thickness in Male Individuals, vol. 9, n.12, doi:10.1371/journal.pone.0114721, PMC 4257718, PMID 25479554.

30. Hu $S, X u$ D, Peterson B, Wang $Q$ \& He X (2013) Association of cerebral networks in resting state with sexual preference of homosexual men: a study of regional homogeneity and functional connectivity, in PLOS ONE, vol. 8, p.e59426, DOI:10.1371/journal.pone.0059426, PMC 36054 12, PMID 23555670.

31. Aste N et al (1998) Anatomical and neurochemical definition of the nucleus of the stria terminalis in Japanese quail (Coturnix japonica)., in J Comp Neurol, vol. 396, n. 2, pp. 141-57, DOI: 10.1002/(SICI)10969861(19980629)396:2<141::AID-CNE1>3.0.CO;20, PMID 9634138.

32. Poiani A (2010) Animal Homosexuality: A Biosocial Perspective, Cambridge University Press, p. 213, ISBN 9781-139-49038-2.

33. Zhou JN (1995) A sex difference in the human brain and its relation to transsexuality, in Nature, vol. 378, $n^{\circ}$ 6552, pp. 68-70, DOI:10.1038/378068a0, PMID 7477289.

34. Savic I, Lindström P (2008) PET and MRI show differences in cerebral asymmetry and functional connectivity between homo- and heterosexual subjects, Proceedings of the National Academy of Sciences of the United States of America, vol. 105, $n^{\circ}$ 27, pp. 94038, doi:10.1073/pnas.0801566105, PMC 2453705, PMID 18 559854.

35. Hill AK, Dawood K \& Puts DA (2012) Biological Foundations of Sexual Orientation, in Handbook of Psychology and Sexual Orientation, illustrated, OUP USA, pp. 55-68, ISBN 978-0-19-976521-8.

36. Witelson SF, Kigar DL, Scamvougeras A, Kideckel DM, Buck B, Stanchev PL, Bronskill M \& Black S (2008) Corpus callosum anatomy in right-handed homosexual and heterosexual men, in Arch. Sex. Behav., vol. 37, $n^{\circ} 6$, pp. 857-63, DOI:10.1007/s10508-007-9276-y, ISSN 15732800 (WC $\cdot$ ACNP), PMID 17975723. 
37. Bailey JM, Zucker KJ (1995) Childhood sex-typed behavior and sexual orientation: a conceptual analysis and quantitative review. Developmental Psychology 31(1):43.

38. LeVay $S$ (2010) Gay, Straight, and the Reason Why: The Science of Sexual Orientation, Oxford University Press, pp. 201-5, ISBN 0-19-975296-6.

39. Ponseti J, Siebner HR, Klöppel S, Wolff S, Granert $O$, Jansen O, Mehdorn HM \& Bosinski HA (2007) Homosexual Women Have Less Grey Matter in Perirhinal Cortex than Heterosexual Women, in PLoS ONE, vol. 2, $n^{o} 8$, p. e762, DOI:10.1371/journal.pone.0000762, PMC 194212 0, PMID 17712410.

40. Friedman RC (1990) Male Homosexuality, New Haven, Yale University Press, p. 312, ISBN 0-300-04745-2.

41. Guillamon A, Junque C \& Gómez-Gil E (2016) A Review of the Status of Brain Structure Research in Transsexualism, in Arch. Sex. Behav., vol. 45, $n^{\circ} 7$, Springer US, pp. 16151648, DOI:10.1007/s10508-016-0768-5, ISSN 15732800 (WC · ACNP), PMC 4987404, PMID 27255307.

42. Berglund H, Lindström P, Savic I (2006) Brain response to putative pheromones in lesbian women, in Proceedings of the National Academy of Sciences of the United States of America, vol. 103, $n^{\circ}$ 21, pp. 826974, DOI:10.1073/pnas.0600331103, PMC 1570103, PMID 16705035.

43. Savic I, Berglund H, Lindström P (2005) Brain response to putative pheromones in homosexual men, in Proceedings of the National Academy of Sciences of the United States of America, vol. 102, $n^{o}$ 20, pp. 735661, DOI:10.1073/pnas.0407998102, PMC 1129091, PMID 15883379.

44. Paul T et al (2008) Brain response to visual sexual stimuli in heterosexual and homosexual males, in Human Brain Mapping, vol. 29, $n^{o} \quad 6, \quad$ pp. 726 35, DOI: $10.1002 / \mathrm{hbm} .20435$, PMID 17636559.

45. Hu SH, Wei $N$ \& Wang $Q D$ (2008) Patterns of brain activation during visually evoked sexual arousal differ between homosexual and heterosexual men., in AJNR Am J Neuroradiol., vol. 29, $n^{o}$ 10, pp. 1890-6, DOI: 10.3174/ajnr.A1260, PMID 18768725.

46. Ponseti J et al (2006) A functional endophenotype for sexual orientation in humans., in NeuroImage, vol. 33, $n^{\circ} 3$, pp.

825 33, DOI:10.1016/j.neuroimage.2006.08.002, PMID 169793 50.

47. Kranz F \& Ishai A (2006) Face Perception Is Modulated by Sexual Preference, in Current Biology, vol. 16, $n^{\circ} 1, p p .63-$ 68, Doi: 10.1016/j.cub.2005.10.070.

48. Sanders $G$, Wright M (1997) Sexual orientation differences in cerebral asymmetry and in the performance of sexually dimorphic cognitive and motor tasks, in Archives of Sexual Behavior, vol. 26, $n^{o}$ 5, pp. 463-80, DOI: 10.1023/A:1024551704723, PMID 9343633.

49. Duffy SM \& Rusbult CE (1985) Satisfaction and commitment in homosexual and heterosexual relationships, in Journal of Homosexuality, vol. 12, nº 2, pp. 1-23.

50. Kinnunen LH, Moltz H, Metz J \& Cooper M (2004) Differential brain activation in exclusively homosexual and heterosexual men produced by the selective serotonin reuptake inhibitor, fluoxetine, in Brain Res, vol. 1024, $n^{\circ} 1$ 2, $\quad$ p . 2514, DOI:10.1016/j.brainres.2004.07.070, PMID 15451388.

51. Safron A, Barch B, Bailey JM, Gitelman DR, Parrish TB \& Reber PJ (2007) Neural correlates of sexual arousal in homosexual and heterosexual men, in Behav Neurosci., vol. 121, $n^{o}$ 2, pp. 237-48, DOI: 10.1037/07357044.121.2.237, PMID 17469913.

52. Safron A et al (2017) Neural Correlates of Sexual Orientation in Heterosexual, Bisexual, and Homosexual Men. In Scientific Reports, volume 7, n. 41314.

53. Safron A et al (2018) Neural Correlates of Sexual Orientation in Heterosexual, Bisexual, and Homosexual Women. In Scientific Reports; 8(1):673, doi: 10.1038/s41598-017-18372-0.

54. Bailey JM et al (2011) Still in Search of Bisexual Sexual Arousal: Comment on Cerny and Janssen. Arch. Sex. Behav. 40, 1293-1295.

55. Cerny JA \& Janssen E (2011) Patterns of sexual arousal in homosexual, bisexual, and heterosexual men. Arch. Sex. Behav. 40, 687-697.

56. Rieger G, Chivers ML \& Bailey JM (2005) Sexual arousal patterns of bisexual men. Psychol. Sci. J. Am. Psychol. Soc. APS 16, 579-584.

57. Tollison CD, Adams HE \& Tollison JW (1979) Cognitive and physiological indices of sexual arousal in homosexual, bisexual, and heterosexual males. J. Behav. Assess. 1, 305314.

58. Rosenthal AM, Sylva D, Safron A \& Bailey JM (2011) Sexual arousal patterns of bisexual men revisited. Biol. Psychol. 88, 112-115.

59. Rosenthal AM, Sylva D, Safron A \& Bailey JM (2012) The male bisexuality debate revisited: Some bisexual men have bisexual arousal patterns. Arch. Sex. Behav. 41, 135-147.

60. Freund K (1974) In Understanding Homosexuality: Its Biological and Psychological Bases (ed. Loraine, D. J. A.), 25-81.

61. Persson TJ, Ryder AG, Pfaus GJ (20106) Comparing Subjective Ratings of Sexual Arousal and Desire in Partnered Sexual Activities From Women of Different Sexual Orientation, Arch Sex Behav, 45 (6), 1391-402, PMID: 25808718, doi: 10.1007/s10508-014-0468-y.

62. Perrotta G (2020) Gender dysphoria: definitions, classifications, neurobiological profiles and clinical treatments. Review article, Author. International Journal of Sexual and Reproductive Health Care, Int J Sex Reprod Health Care, 3(1): 042-050, doi: http://dx.doi.org/10.17352/ijsrhc.000013.

63. Perrotta G (2020) Dysfunctional attachment and psychopathological outcomes in childhood and adulthood. Open Journal of Trauma, Open Journal of Trauma, Open J Trauma 4(1): 012-021, doi https://dx.doi.org/10.17352/ojt.000025.

64. Perrotta G (2020) Pedophilia: definition, classifications, criminological and neurobiological profiles and clinical treatments. A complete review. Open Journal of Pediatrics and Child Health, Open J Pediatr Child Health, 5(1): 019026, doi: http://dx.doi.org/10.17352/ojpch.000026.

65. Perrotta G (2020) Psychological trauma: definition, clinical contexts, neural correlations and therapeutic approaches. Current Research in Psychiatry and Brain Disorders. Curr Res Psychiatry Brain Disord: CRPBD- 100006.

66. Ganna A et al (2016) Large-scale GWAS reveals insights into the genetic architecture of same-sex sexual behaviour, in Science, vol. 365, Issue 6456, eaat7693, doi: 10.1126/science.aat7693.

67. Bao AM, Swaab DF (2011) Sexual Differentiation of the Human Brain: Relation to Gender Identity, Sexual Orientation and Neuropsychiatric Disorders. In Front Neuroendocrinol, $32 \quad$ (2), 214-26, doi: 10.1016/j.yfrne.2011.02.007, PMID: 21334362. 
68. Bao AM, Swaab DF (2010) Sex Differences in the Brain, Behavior, and Neuropsychiatric Disorders. In Neuroscientist, $\quad 16 \quad$ (5), 550-65, doi: 10.1177/1073858410377005, PMID: 20889965.

69. Brecht $\mathrm{M}$ et al (2018) Socio-sexual processing in Cortical Circuits. In Curr Opin Neurobiol, 52, 1-9, doi: 10.1016/j.conb.2018.04.003, PMID: 29694921.
70. Perrotta G (2020) The strategic clinical model in psychotherapy: theoretical and practical profiles. Journal of Addiction and Adolescent Behaviour, $\mathrm{j}$ Addi Adol Beh, 3(1), doi: 10.31579-007/2688-7517/016.
Ready to submit your research? Choose Auctores and benefit from:

* fast, convenient online submission

* rigorous peer review by experienced research in your field

* rapid publication on acceptance

* authors retain copyrights

* unique DOI for all articles

* immediate, unrestricted online access

At Auctores, research is always in progress.

Learn more www.auctoresonline.org/journals/neuroscience-andneurological-surgery 